\title{
Metodologia de rating em cooperativas agropecuárias: um estudo de caso
}

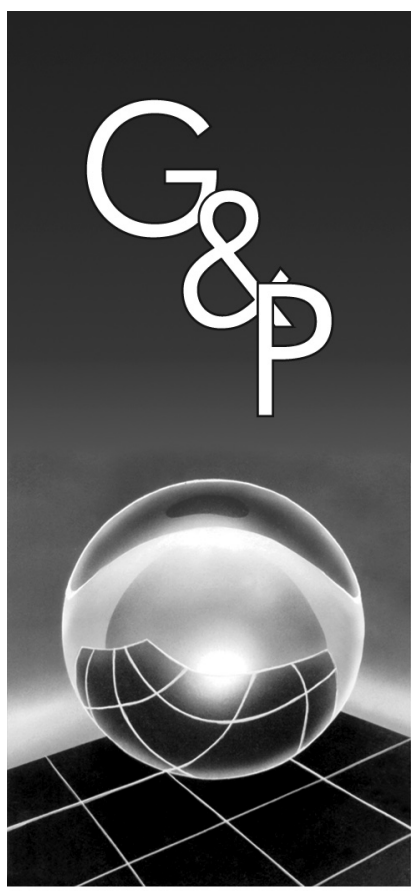

Davi Rogério de Moura Costa Sigismundo Bialoskorski Neto

Resumo

A partir do início da década de 90, ocorreram diversas mudanças no ambiente institucional do cooperativismo brasileiro, em função dos problemas macroeconômicos que elevaram a alavancagem e a necessidade de as cooperativas obterem recursos financeiros junto a terceiros. Essa situação se intensificou nos últimos anos para manter a competitividade das organizações cooperativas no mercado. Em função da importância desse novo cenário, procurou-se estudar mecanismos de sinalização, com o objetivo de reduzir a assimetria de informações entre o mercado e os gestores das cooperativas. Assim, este trabalho desenvolve uma metodologia de rating para ser aplicada em cooperativas agropecuárias de forma a reduzir os problemas de seleção adversa e risco moral (moral hazard), que geram ineficiência no relacionamento entre essas organizações e o mercado financeiro; objetiva-se, também, averiguar a sua aplicabilidade, por meio de um estudo de caso. A partir dos resultados alcançados, é possível concluir que a metodologia é aplicável e que o sinalizador gerado, bem como as avaliações e os pesos, deveriam ser discutidos em comitês de rating, a exemplo do que é feito pelas agências especializadas. Como consideração final, é sugerida uma agenda de novas aplicações da metodologia para testá-la junto a outras organizações, de forma a consolidá-la como um sinalizador a ser usado pelo mercado e pelo sistema cooperativo.

Palavras-chave: Cooperativas. Rating. Auditoria. Risco.

\section{Introdução}

A Aliança Cooperativa Internacional define que cooperativa é uma associação autônoma de pessoas que se unem voluntariamente para satisfazer suas aspirações e necessidades econômicas, sociais e culturais comuns, por meio de uma empresa de propriedade coletiva, gerida democraticamente.

Costa e Bialoskorski Neto (2004) relatam que, a partir da promulgação da Constituição Federal de 1988 estabelecendo a autogestão do sistema cooperativo brasileiro, cria-se um ambiente institucional propício para a existência de uma mais intensa assimetria de informações e que, a partir de 1991, há uma maior necessidade de capitalização junto a terceiros, devido ao encerramento das atividades do Banco Nacional de Crédito Cooperativo (BNCC).

Ao estudar as especificidades do empreendimento cooperativo, Bialoskorski Neto (1994) e Requejo (1997) relatam que essas organizações têm objetivos diferentes das demais empresas que objetivam lucro e que, portanto, as avaliações acerca da sua gestão e da capacidade de pagamento deveriam ser realizadas por outra ótica. Assim, não se devem analisar somente os indicadores econômico-financeiros, mas também aqueles que apresentam o desempenho social.

Costa e Bialoskorski Neto (2004) estudam as propostas de metodologia para avaliação de risco de crédito de cooperativas e concluem que não existe uma proposta de metodologia com indicadores e modelos específicos para ações da economia social.

Portanto, é objetivo central deste artigo apresentar uma metodologia de rating para avaliar especificamente as organizações cooperativas agropecuárias e, de forma complementar, proceder à aplicação da metodologia em um estudo de caso para verificar se a metodologia apresentada é aplicável e os possíveis problemas dessa aplicação.

Para isso, o trabalho foi dividido em diferentes seções: inicialmente, é exposto o referencial teórico para, depois, apresentar-se a metodologia desenvolvida. Em sequência, apresentam-se os resultados da sua aplicação empírica 
numa cooperativa, um estudo de caso, para então expor algumas considerações finais.

\section{Referencial teórico}

Para Milgrom e Roberts (1992), a assimetria de informação ocorre nos mercados e em relações contratuais, nas quais um agente econômico possui uma informação que o outro desconhece. Akerlof (1970) explana que a assimetria de informação é prejudicial ao funcionamento dos mercados, uma vez que sua principal consequência é a de impor dificuldades para a realização de transações econômicas entre os detentores dos produtos de alta qualidade e os respectivos compradores. Stiglitz e Weiss (1981) apontam que a assimetria de informações impacta no spread bancário, faz com que as taxas de juros subam, o que poderá conduzir ao mercado financeiro somente os tomadores de recursos mais necessitados e, portanto, com pouca capacidade de pagamento.

Spence (1973) propõe como solução à seleção adversa os mecanismos de sinalização, que consistiriam em um agente econômico enviar um sinal ao mercado, transmitindo todas as informações que julgar relevantes de forma a reduzir a disparidade das informações a seu respeito. De acordo com Bergamini Junior (2000), a teoria da administração financeira apresenta o rating como o processo de análise elaborado com o objetivo de determinar a capacidade e a vontade de uma entidade vir a cumprir, no período adequado e na íntegra, determinadas responsabilidades, podendo ser estas informações resumidas, sintéticas e comparáveis. Assim, essa análise poderia ser considerada como um mecanismo de sinalização e de redução da assimetria de informações.

Considerando-se que a palavra 'risco' representa a probabilidade de ocorrer um evento não desejado e que rating é o processo de análise deste, então o resultado final do processo de avaliação de uma organização determinará a probabilidade de a empresa não cumprir suas responsabilidades junto aos agentes do mercado. Portanto, o rating corporativo pode ser considerado como parâmetro importante no relacionamento contratual entre dois agentes econômicos; na medida em que é elaborado a pedido de firmas interessadas em divulgar ao mercado o seu nível de risco, de forma a aumentar a transparência e confiabilidade na sua gestão, funciona assim como um sinalizador ao mercado. Segundo a Moody's (2004), as vantagens de se obter uma boa classificação podem ser:

a) menor valor de prêmio ou spread em suas operações;

b) maior valorização de suas ações;

c) maior atratividade de investimento externo;

d) melhoria na imagem institucional; e

e) maior facilidade na obtenção de financiamentos.
De acordo com Silva (1997) e Weston e Brigham (2000), as metodologias de rating que avaliam o risco de crédito de empresas estão embasadas nos denominados "C's" do crédito, definidos na literatura da administração financeira; cada um deles representa um grupo de indicadores que os analistas deveriam abordar, como: caráter, capacidade, condições, conglomerado, capital e colateral.

O primeiro grupo - caráter - aponta a intenção da empresa em cumprir seus compromissos; o segundo capacidade - está relacionado com o potencial da gestão, com base em fatos escriturados passados, em honrar suas dívidas. O terceiro grupo - condições - tem por objetivo informar acerca das tendências econômicas do mercado onde a empresa atua, se o ambiente institucional contribuirá para que ela efetive suas obrigações contratadas. O conglomerado - quarto grupo - relata a condição societária da empresa que está sendo avaliada, ou seja, se a sua condição de sócia ou acionista de outras empresas poderá contribuir para a sua situação financeira. O quinto grupo, capital da empresa, como o próprio nome aponta, se refere à situação econômica e financeira da empresa analisada e, finalmente, o sexto "C" - colateral - informa acerca do nível de garantias que a empresa poderia disponibilizar para um contrato de crédito.

Há na literatura trabalhos que se preocuparam em determinar ou discutir metodologias de determinação da solvência e do desempenho em cooperativas; pode-se classificar esse esforço acadêmico em dois grupos distintos, quanto às finalidades que possuem para analisar o desempenho econômico-financeiro de uma cooperativa.

No primeiro grupo, estão os trabalhos de Fischer e Moore (1986), Araújo (1996), Requejo (1997), Menegário (2000), Gimenes e Opaso (2001), Moody's (2004) e o Sistema de Acompanhamento e Análise de Cooperativa - SAAC, que têm como objetivo a classificação das cooperativas para averiguar sua condição de solvência. No segundo grupo, estão os trabalhos de Oliveira Junior (1991), Bialoskorski Neto (2000) e Bialoskorski Neto, Nagano e Moraes (2006), que apresentam metodologias de avaliação de cooperativas com base no acompanhamento do desenvolvimento econômico, financeiro e social.

Dentre as propostas metodológicas estudadas, o SAAC, utilizado pela Organização das Cooperativas do Estado do Paraná - OCEPAR e a proposta metodólogica da Moody's são as únicas específicas para elaboração de rating para cooperativas agropecuárias. Porém, a metodologia da Moody's, desenvolvida especificamente para analisar as organizações cooperativas americanas, não se aplica ao ambiente institucional brasileiro e a da OCEPAR, por ser executada por entidade de representação, não pode ser definida propriamente como metodologia de rating.

Todavia, delineiam a execução da proposta, apresentada na sequência, pois contemplam os C's do crédito que 
também são aspectos importantes para a avaliação de cooperativas agropecuárias.

\section{Proposta metodológica}

A metodologia, discutida em detalhes e desenvolvida por Costa (2005), foi dividida em cinco grupos de indicadores assim denominados: capacidade da organização; capital da organização; caráter da organização; colateral e conglomerado, e condição de mercado. Estes grupos, no total, englobam 12 tópicos e 27 indicadores.

Assim, a avaliação se inicia pela análise dos indicadores que irão compor os tópicos e depois pelo conjunto de tópicos que irão formar a avaliação do grupo; dessa forma, a avaliação final será composta por cinco avaliações referentes a cada um dos grupos. Cada indicador recebe um peso que varia de 1 a 3 , em ordem crescente. Deste modo, como exemplo, se o valor obtido foi o mais adequado, ele recebe peso três; se sua adequação é mediana, a esse se aplica o peso dois; e, se o resultado apontou dificuldades de adequação, esse recebe o peso um. De acordo com a avaliação de cada um dos indicadores, e seus respectivos pesos, há a formação do conceito do tópico.

Assim, o tópico recebeu conceitos que variaram entre a, b ou c, de acordo com a avaliação do conjunto de indicadores e seus respectivos pesos que compunham o tópico. A Equação (1) aponta como é calculado o conceito obtido em determinado tópico, de acordo com os pontos obtidos pela análise da cooperativa.

$$
P_{o}=\sum_{1}^{n} P_{n}
$$

em que: $P_{o}=$ total de pontos obtidos nos indicadores analisados; e $P_{n}=$ ponto obtido no indicador $\mathrm{n}$.

Assim, como critério, se em determinado tópico os pontos obtidos $P_{o} \geq 75 \%$ dos pontos possíveis de obtenção (PP), a avaliação desse tópico recebe o conceito a; se $50 \% \leq P_{o}<75 \%$ de PP, a avaliação obtém b, e se $P_{o}<50 \%$ de PP, obtém c.

De forma semelhante, os grupos são formados por vários tópicos e são classificados também com conceitos A, B e C, de acordo com o conjunto de conceitos recebidos pelo conjunto de tópicos que faz parte do grupo avaliado, conforme a Equação 2:

$$
T P=3 a+2 b+c
$$

na qual: $T P=$ total de pontos obtidos; $a=$ número de avaliações a recebidas; $b=$ número de avaliações $b$ recebidas; $c=$ igual número de avaliações c recebidas; e 3, 2 ou 1 é a respectiva ponderação para cada somatório de pontos

Também, se para o grupo o total alcançado de pontos $\mathrm{TP} \geq 75 \%$ dos pontos possíveis (PP), a avaliação da cooperativa recebe conceito A; se $50 \% \leq P_{o}<75 \%$ de PP, a avaliação recebe conceito $\mathrm{B}$, e se $\mathrm{TP}<50 \%$ de $\mathrm{PP}$, a avaliação obtém conceito $C$.

A Tabela 1 mostra o conjunto dos grupos, tópicos e indicadores utilizados para a análise; a escolha ocorreu após um esforço de discussão de cada uma dessas variáveis, processo este que está detalhado em Costa (2005).

O grupo capacidade da cooperativa indica se a cooperativa cumpre seus compromissos no curto prazo e no ambiente institucional vigente. Para gerar essa informação, o grupo foi dividido nos tópicos: capacidade da cooperativa cumprir sua função social (ES); estratégia empresarial da cooperativa com o cooperado (EECC); eficiência empresarial enquanto organização (EEO), e profissionalização e qualidade da governança (PQG).

A avaliação da capacidade de a cooperativa cumprir sua função social (ES) diagnostica a relação econômica da cooperativa com o cooperado, ou seja, o desempenho de atividades econômicas que proporcionariam aumentos na renda do associado, oportunidade de comercialização da produção e fornecimento de insumos, bens e serviços necessários à atividade econômica do sócio, de forma a impulsionar seu desempenho econômico e financeiro. Os indicadores que compõem o tópico são: índice de atividade econômica do cooperado com a cooperativa (ATc); índice de abrangência do quadro social (AQS), e índice de participação dos cooperados em assembleia geral (PAG).

O tópico Estratégia Empresarial da Cooperativa com o Cooperado (EECC) informa acerca da forma como a cooperativa gera sua relação econômica com o cooperado. Portanto, avalia as estratégias empresariais adotadas pela cooperativa junto aos cooperados e como essas contribuem para aumentar a capacidade da cooperativa de cumprir seus compromissos contratados.

Para gerar informações relativas a esse tópico, englobaram-se os indicadores: índice de cobertura do financiamento efetuado pela cooperativa ao cooperado (CFCC); estratégia de capitalização da cooperativa via cooperado (ECVC); planos de devolução do capital social ao cooperado (PDCC); remuneração do capital social dos cooperados (RCSC); prestação de serviços ao cooperado (PSC), e ciclo financeiro da cooperativa junto ao cooperado (CFINC).

O CFCC apresenta a forma como a cooperativa se resguarda da estratégia de financiamento das atividades do cooperado. Caso forneça crédito ao cooperado, então, quanto maior o CFCC, mais seguro é o sistema de garantias das operações.

$\mathrm{O}$ indicador ECVC informa se a cooperativa possui programas formais de capitalização via cooperado e se esses podem ser dados como garantia de operações que a cooperativa venha a realizar no mercado. Seu diagnóstico é feito por meio de análise do estatuto social da cooperativa e de entrevistas junto aos seus diretores. 
Tabela 1. Indicadores, tópicos e grupos considerados na avaliação de cooperativas agropecuárias.

\begin{tabular}{|c|c|c|c|c|c|}
\hline Grupo & Tópicos & Indicador & $\begin{array}{l}\text { Valor/pontos } \\
\text { indicador }\end{array}$ & $\begin{array}{c}\text { Avaliação do } \\
\text { tópico }\end{array}$ & Avaliação do grupo \\
\hline \multirow[t]{4}{*}{$\begin{array}{l}\text { Capacidade da } \\
\text { organização }\end{array}$} & Eficiência Social (ES) & $\begin{array}{l}\text { ATc } \\
\text { PAG }\end{array}$ & & & \\
\hline & $\begin{array}{l}\text { Estratégia Empresarial da } \\
\text { Cooperativa com o Cooperado } \\
\text { (EECC) }\end{array}$ & $\begin{array}{c}\text { CFCC } \\
\text { ECVC } \\
\text { PDCC } \\
\text { RCSC } \\
\text { PSC } \\
\text { CFINC }\end{array}$ & & & \\
\hline & $\begin{array}{l}\text { Eficiência Empresarial enquanto } \\
\text { Organização (EEO) }\end{array}$ & $\begin{array}{l}\overline{\mathrm{IPM}} c \\
\mathrm{CFIN} \\
\mathrm{MOC} \\
\mathrm{GAP}\end{array}$ & & & \\
\hline & $\begin{array}{l}\text { Profissionalização e qualidade da } \\
\text { governança (PQG) }\end{array}$ & $\begin{array}{l}\text { RCE } \\
\text { FHE } \\
\text { EFG }\end{array}$ & & & \\
\hline \multirow[t]{6}{*}{$\begin{array}{l}\text { Capital da } \\
\text { organização }\end{array}$} & Capital Social do Cooperado (CSC) & $\begin{array}{l}\mathrm{CS}_{\mathrm{C}} \\
\mathrm{CSG}\end{array}$ & & & \\
\hline & Endividamento (END) & $\begin{array}{l}\text { GCFE } \\
\text { DLPC } \\
\text { DCPC } \\
\text { GDter }\end{array}$ & & & \\
\hline & Autofinanciamento (AUTFIN) & $\begin{array}{l}\text { IAF } \\
\text { CGD } \\
\text { NCG }\end{array}$ & & & \\
\hline & Liquidez (LIQ) & $\begin{array}{l}\mathrm{LC} \\
\mathrm{LS}\end{array}$ & & & \\
\hline & $\begin{array}{l}\text { Rentabilidade } \\
\text { (RENT) }\end{array}$ & $\begin{array}{l}\mathrm{MgL} \\
\mathrm{RSA} \\
\mathrm{RSPL}\end{array}$ & & & \\
\hline & Solvência (SOLV) & KANITZ & & & \\
\hline $\begin{array}{l}\text { Caráter da } \\
\text { organização }\end{array}$ & $\begin{array}{l}\text { Pontualidade } \\
\text { Protestos e desabonos }\end{array}$ & & & & \\
\hline \multicolumn{6}{|c|}{ Colateral e conglomerado } \\
\hline
\end{tabular}

Fonte: Costa (2005).

O PDCC avalia se a cooperativa planeja a restituição do capital do cooperado e se essa estratégia não compromete sua estrutura financeira; a análise é feita por meio de entrevistas com diretores e de averiguações no estatuto social.

A avaliação do item RCSC é feita para obter informações acerca de como a cooperativa utiliza essa estratégia para atrair o capital do cooperado e se isso não expõe suas finanças ao risco. Seu diagnóstico também é realizado por meio de entrevistas junto aos diretores e complementado por averiguações nos seus demonstrativos contábeis e estatuto social.

O PSC é diagnosticado com a finalidade de averiguar se a cooperativa presta serviços aos cooperados como estratégia de atratividade e se essa não compromete a sua estrutura financeira. As informações são obtidas por entrevistas junto aos diretores e diagnosticadas com base nos controles de custos da cooperativa.

O CFINC indica as características da relação comercial da cooperativa com o associado e informa acerca da periodicidade de pagamento e recebimento entre ambos. Quanto menor o valor de CFINC, mais adequada é a política comercial da cooperativa em relação ao cooperado, ou seja, a cooperativa não expõe suas finanças ao risco para praticar políticas de prazos junto ao cooperado.

Com base nos pesos recebidos em cada um dos indicadores e utilizando a Equação (1), define-se a avaliação para o tópico EECC. 
O tópico eficiência empresarial da cooperativa enquanto organização (EEO) apresenta a capacidade da cooperativa como empresa; utiliza os seguintes indicadores: índice de participação média da cooperativa no mercado regional (IPM $c$ ); ciclo financeiro da cooperativa (CFIN); margem operacional (MOC), e giro dos ativos permanentes (GAP).

O cálculo do $\overline{\mathrm{IPM}} c$ é feito considerando as principais atividades comerciais e os serviços prestados pela cooperativa, que indicam sua importância econômica na região de atuação. A MOC informa acerca da competência dos gestores em administrar as obrigações da organização, enquanto que o GAP apresenta como os gestores atuam em relação à imobilização de recursos próprios. Assim, quanto maior o valor desses três indicadores, melhor será a eficiência empresarial da cooperativa.

O CFIN apresenta a eficiência comercial da cooperativa, informando como os gestores administram seu fluxo de caixa; quanto menor o valor desse indicador, mais eficiente é a sua gestão.

Os indicadores MOC, GAP e CFIN devem ser comparados com os resultados médios de outras cooperativas agropecuárias que atuam na mesma atividade e, somente após essa comparação, deve-se emitir o peso de cada um.

Depois de calculados os indicadores e gerados os pesos, é emitida uma avaliação para o tópico EEO, conforme Equação (1).

Para avaliar o tópico profissionalização e qualidade da governança (PQG), a metodologia propõe o uso de indicadores que forneçam informações relevantes acerca dos gestores da cooperativa: relação contratual dos executivos com a cooperativa (RCE); formação e histórico dos executivos (FHE), e efetividade do conselho fiscal em relação aos atos dos gestores da cooperativa (EFG).

O indicador RCE verifica o papel e a importância do executivo no desempenho da cooperativa. O FHE informa acerca da capacitação dos principais executivos, enquanto que o EFG indica se o conselho fiscal atua garantindo uma gestão transparente dos atos administrativos dos gestores da cooperativa junto ao quadro social.

A partir da análise de cada um dos indicadores, é emitido seu peso e, utilizando-se da Equação (1), emite-se uma avaliação para o tópico. Com base nas avaliações emitidas para cada tópico e utilizando a Equação (2), emite-se a avaliação do grupo Capacidade da Organização.

O segundo grupo de indicadores da metodologia, denominado Capital da Organização, indica a situação econômica e financeira da cooperativa, averigua se sua condição financeira permite cumprir os compromissos contratados.

Para gerar uma avaliação que transmita essas informações, são diagnosticados os tópicos: capital social do cooperado (CSC); endividamento (END); autofinanciamento (AUTFIN); liquidez (LIQ); rentabilidade (RENT), e solvência (SOLV).
O tópico capital social do cooperado (CSC) relata como a cooperativa faz sua alavancagem financeira via cooperado, utilizando os indicadores capital social por cooperado (CSc) e capital social utilizado no giro (CSG).

O CSc aponta a motivação do cooperado em transacionar com a cooperativa e quanto maior seu valor, maior será o montante de capital social disponível à cooperativa. Já o CSG informa o montante da necessidade de capital de giro da cooperativa que é suprido pelo capital social do cooperado; quanto maior o seu valor, consequentemente menor será a dependência da cooperativa por capital de terceiros no curto prazo. Com base nos pesos dados a cada indicador, é dada a avaliação para o tópico (CSC), conforme Equação (1).

Os indicadores utilizados para aferir o tópico endividamento (END) demonstram a importância dos recursos de terceiros no financiamento da cooperativa e o grau de comprometimento da sua estrutura financeira. Os valores diagnosticados são usados para averiguar a capacidade de a cooperativa cumprir seus compromissos financeiros.

Para avaliar esse tópico, utilizam-se os indicadores: grau de comprometimento do faturamento bruto da cooperativa com o endividamento junto a terceiros (GCFE); distribuição do endividamento total quanto ao curto (DCPC) e longo prazo (DLPC), e grau de dependência de capital de terceiros para operacionalizar suas atividades (GDter).

O GCFE informa o quanto da dívida é saldado se todo o faturamento for destinado exclusivamente para essa finalidade; quanto menor for seu valor, melhor a gestão financeira da cooperativa. A distribuição das dívidas quanto ao prazo de vencimento (DLPC - DCPC) realça qual sua predominância, se no longo ou curto prazo. $\mathrm{O}$ GDter informa acerca da dependência da cooperativa por captação de recursos no mercado para executar suas operações; quanto menor seu valor, melhor a situação financeira da organização. Com base nos pesos recebidos de cada indicador, é gerada uma avaliação para o tópico endividamento (END), conforme Equação (1).

O autofinanciamento (AUTFIN) da cooperativa informa a capacidade dos gestores em administrar suas operações com capital próprio e, para gerar essa informação, serão diagnosticados os indicadores: quantidade de capital de giro disponível (CGD), necessidade de capital de giro (NCG) e índice de autofinanciamento (IAF). O CGD representa o total de recursos necessários, no curto prazo, para a cooperativa realizar suas operações. O NCG informa a quantidade de recursos necessários para realizar as operações. Por fim, o índice de autofinanciamento relaciona o CGD e a NCG, informando acerca da real necessidade de capital pela cooperativa.

O IAF diagnostica a capacidade de a organização financiar suas necessidades de capital de giro com capital próprio; assim, quanto maior seu valor, melhor será sua condição financeira. Como o IAF é a relação entre a necessidade 
de capital de giro com capital de giro disponível, então, baseado em seu valor, será emitida uma avaliação para informar o tópico autofinanciamento.

Para Brigham e Houston (1999), a posição de liquidez da empresa indica se essa consegue saldar suas dívidas, à medida que estas forem vencendo, durante o seguinte exercício social. Para gerar essa informação, os autores propõem os indicadores de liquidez corrente e seca. Costa (2005) propõe a utilização desses mesmos indicadores e, a partir dos seus valores, emite uma avaliação para o tópico liquidez (LIQ), conforme Equação (1).

A rentabilidade, de acordo com Brigham e Houston (1999), é o resultado de uma série de políticas e decisões tomadas pela administração da empresa. Baseado na definição dos autores, Costa (2005) utiliza os indicadores margem líquida (MgL), retorno sobre os ativos (RSA) e retorno sobre o patrimônio líquido (RSPL).

A margem líquida $(\mathrm{MgL})$ apresenta o nível de segurança que a cooperativa aplica sobre a unidade vendida, de forma a garantir o seu funcionamento; quanto maior $\mathrm{MgL}$, melhor a condição financeira da cooperativa.

O retorno sobre o ativo total informa sua rentabilidade para a cooperativa e o retorno sobre o patrimônio líquido indica a taxa de retorno sobre os investimentos dos cooperados. Quanto maiores esses valores, melhor a rentabilidade da cooperativa.

Após avaliar os indicadores e compará-los com os de outras cooperativas agropecuárias que atuam na mesma atividade, é gerado um peso para cada indicador. E usando a Equação (1), é gerada a avaliação para representar o tópico rentabilidade da cooperativa (RENT).

O índice de Kanitz é calculado para indicar a solvência (SOLV) da cooperativa e, baseando-se no seu valor, é emitida a avaliação para o tópico solvência (SOLV). Esse critério - como referido - é aplicado no SACC já há algum tempo, o que oferece um parâmetro complementar de análise. Com base nas avaliações recebidas em cada tópico e utilizando a Equação (2), é gerada a avaliação do grupo Capital da Organização.

O Caráter da Organização informa a intenção da cooperativa em cumprir seus compromissos no curto prazo e no ambiente institucional vigente. Para poder gerar essa informação, a metodologia propõe que sejam diagnosticados os tópicos: pontualidade nos pagamentos e existência de protestos e desabonos. A pontualidade dos pagamentos é avaliada, conforme sugerido por Silva (1997), junto às agências de informações comerciais e bancárias, priorizando os itens: dias de atraso de pagamento e frequência dos atrasos. Para diagnosticar os indicadores, é necessário verificar o valor do indicador CFIN, questionar os gestores e checar, junto ao setor competente, os seguintes pontos: quantas vezes a cooperativa atrasou os pagamentos no último exercício social e em quantos dias consistiu esse atraso; a partir destes dados, emite-se uma avaliação para o tópico.

A avaliação da existência de protestos e desabonos deve ser feita junto às empresas que prestam esse tipo de serviço ao mercado, ou seja, cartórios de protestos de títulos e empresas que são especializadas em informar históricos negativos - como exemplos, o SERASA e o Serviço de Proteção ao Crédito (SPC). É recomendável que a informação seja referente aos três últimos exercícios sociais, de forma a considerar um período de tempo próximo ao que as empresas caracterizam como histórico negativo e disponibilizam no mercado. A partir dos resultados, deve ser emitida uma avaliação para esse tópico.

Com base nas avaliações recebidas nos dois tópicos que compõem esse grupo e utilizando a Equação (2), é gerada a avaliação do grupo Caráter da Organização.

O grupo Colateral e Conglomerado englobou informações relativas à relação societária da cooperativa com as demais empresas ou cooperativas e seu nível de garantias para possíveis operações de crédito. Com base nas informações coletadas nesse grupo e na pontuação estabelecida, conforme Equação (1), é emitida a avaliação do grupo.

A Condição de Mercado apresenta informações relativas ao ambiente macroeconômico no qual a cooperativa atua e permite inferir se a cooperativa tem condições internas e externas para cumprir seus compromissos nos prazos assumidos. Para gerar a informação, é preciso que sejam diagnosticados os riscos do setor onde a cooperativa atua, o ambiente político, econômico e regulatório, e o nível de apoio do estado em relação às suas atividades. Com base nas análises das informações coletadas para esse grupo, é emitida sua avaliação.

\section{Teste de aplicação da metodologia: estudo de caso}

A cooperativa estudada desenvolve atividades ligadas à agropecuária, é localizada no estado de São Paulo e atua no agronegócio café. A organização fornece crédito para custear as atividades do cooperado, insumos e assistência técnica; recebia e armazenava a produção do sócio, chegando até mesmo a industrializar e comercializar seu café, tanto no mercado interno como no externo. A evolução do número de cooperados foi de 905 , no ano de 2000, para 1.637 em 2004, ou seja, um crescimento de aproximadamente $15,9 \%$ ao ano e uma expansão no quadro social de aproximadamente $63,6 \%$ no período. $\mathrm{Na}$ mesma trajetória do número de cooperados, o faturamento da cooperativa evoluiu $14,61 \%$ ao ano e $58,4 \%$ no mesmo período; a quantidade de café recebida e comercializada também cresceu 45 e $42 \%$, respectivamente. Os dados referentes ao faturamento da cooperativa, seu patrimônio líquido e vendas são apresentados na Tabela 2 e mostram 
Tabela 2. Informações financeiras, em milhões de reais corrigidos pelo IGP-DI base julho/05, que apresentam o recente crescimento da cooperativa.

\begin{tabular}{crrrrr}
\hline Dados & \multicolumn{5}{c}{ Ano } \\
\cline { 2 - 6 } & $\mathbf{2 0 0 0 *}$ & $\mathbf{2 0 0 1 *}$ & $\mathbf{2 0 0 2} *$ & $\mathbf{2 0 0 3}^{*}$ & $\mathbf{2 0 0 4}$ \\
\hline Faturamento bruto & 86,72 & 88,43 & 101,58 & 106,81 & 149,65 \\
Patrimônio líquido & 10,90 & 10,96 & 9,03 & 12,70 & 17,59 \\
Vendas no período & 86,04 & 87,97 & 100,97 & 105,68 & 148,74 \\
\hline
\end{tabular}

Fonte: relatórios de gestão da cooperativa.

que a cooperativa está se consolidando no mercado, haja vista sua constante evolução.

A partir da aplicação da metodologia, foi possível dividir os indicadores utilizados para elaboração do rating em dois grupos: os aplicados na íntegra e os que sofreram adaptação. Neste trabalho, por limitação de espaço, são apresentados somente os indicadores que precisaram de adaptação ou que não se aplicavam diretamente a um dos C's do crédito,

Somente o indicador abrangência do quadro social (AQS) não foi possível de ser calculado, pois o número total de produtores de café, na região de atuação da cooperativa, não foi encontrado nas bases de dados consultadas. $\mathrm{O}$ dado encontrado, que poderia ser usado como proxy, foi o número de Unidades de Produção Agropecuária (UPA), fornecido pelo projeto Levantamento das Unidades de Produção Agropecuária (LUPA); contudo, tal dado mostra-se válido somente para o ano de 1997 e essa informação não foi considerada consistente para 2004. Como solução para futuras aplicações, sugere-se que, em vez do número de produtores que exercem a mesma atividade na região de atuação, seja diagnosticado e usado como proxy o porcentual da área total ocupada pelo produto estudado, que está sendo movimentada pelos produtores cooperados.

Os indicadores que sofreram adaptação foram: Atc, PAG, CFCC, $\overline{\mathrm{IPM}} c$, CFIN, MOC, GAP, MgL, RSA e RSPL. O indicador ATc não foi calculado da forma originalmente prevista, pois a cooperativa não tinha dados que pudessem gerá-lo. O cálculo foi feito com base numa estimativa que a cooperativa havia realizado no ano de 2003 , que consistia em averiguar quantos cooperados, do total do quadro social, enviaram seu café, na totalidade ou apenas parte dele, para cooperativa nos anos de 2000 a 2003. O significado do indicador, da forma como foi efetuado, ficou aquém do almejado, pois não representou qual o porcentual de cooperados que transaciona mais de $80 \%$ do seu potencial econômico e financeiro com a cooperativa; esse fato, porém, não inviabilizou a aplicação do indicador.

O PAG, da forma como proposto na metodologia, não foi possível ser calculado, pois a cooperativa não efetua o acompanhamento do número de cooperados ativos. Então, a sua forma de cálculo passou a ser feita pela relação entre o número de cooperados presentes na assembleia e o número total de cooperados. Para calcular o CFCC, era preciso estimar o valor das garantias reais que a cooperativa tem em seu poder. Como a cooperativa não efetua esse cálculo regularmente, foi necessário estabelecer uma metodologia que apresentasse esse valor. Nesse sentido, foi proposto que a cooperativa transformasse as garantias em sua posse em valores correntes, ou seja, transformar as notas promissórias rurais (NPR), dadas pelos cooperados, em valores correntes.

O IPMc foi calculado para três atividades: armazenamento, comercialização e industrialização do café produzido na região. Para as atividades de assistência técnica, fornecimento de insumos e fornecimento de créditos, a cooperativa não possuía informações a respeito, de forma que não foi possível chegar ao índice de participação naquelas atividades. $\mathrm{O}$ cálculo não foi ponderado conforme sugeria a metodologia, pois os demonstrativos da cooperativa não permitiam chegar à participação de cada atividade no seu desempenho. Nesse sentido, fez-se a média simples dos valores.

Os indicadores ciclo financeiro (CFIN), margem operacional da cooperativa (MOC) e giro do ativo permanente (GAP) precisaram ter alterada a forma de comparação, pois a cooperativa não tinha esses valores disponíveis. A solução foi comparar os valores obtidos com o valor médio das cooperativas agropecuárias paranaenses, pois a OCEPAR é única organização que tem dados disponíveis desde 1990.

A forma de análise, baseada na leitura atenta de documentos, como o estatuto social e o regimento interno da cooperativa, não apresentou maiores dificuldades. É importante lembrar que a entrevista com os diretores demanda que o avaliador tenha previamente feito a leitura dos documentos da cooperativa e que tenha definido o horizonte de análise, pois a cooperativa pode estar pretendendo executar algumas atividades, mas o fato de ainda não fazê-lo é que deverá ser levado em consideração. Outro ponto a ser observado é o fato de o questionário aplicado para averiguar a efetividade da fiscalização ter sido respondido apenas pelo membro coordenador do conselho fiscal do ano de 2004; crê-se que o resultado poderia ser mais conclusivo se esse questionário tivesse sido aplicado a todos os conselheiros fiscais, inclusive suplentes.

Em relação ao grupo capital da organização, os indicadores MgL, RSA e RSPL precisaram ter alterada a forma de comparação. A metodologia original propunha que seus valores fossem comparados com os das cooperativas que atuavam na mesma atividade, mas esses valores não estavam disponíveis. Como solução, fez-se a comparação dos valores dos indicadores com o valor médio das cooperativas agropecuárias do Estado do Paraná, pois a OCEPAR é única organização, como referido, que tem dados disponíveis desde 1990. Entretanto, de forma similar ao grupo anterior, a falta de dados não invalida a aplicabilidade da metodologia. 
Para averiguar o caráter da organização, durante a aplicação da metodologia se conseguiram apenas as informações fornecidas pela própria cooperativa, quando, na verdade, deveria se buscar parte dessas informações no mercado, sobretudo aquelas que informam se existe default da organização. Da mesma forma, os grupos colateral e conglomerado também foram averiguados segundo informações originadas na cooperativa, em entrevistas com diretores ou retiradas dos demonstrativos contábeis, quando o ideal seria a contratação de peritos para uma avaliação adequada dos bens em termos de valoração do patrimônio. Porém, é importante ressaltar que todas essas informações existem e podem ser adquiridas no mercado; portanto, a abordagem, mesmo não sendo a ideal, não deve ser motivo para inviabilizar a metodologia.

Para a averiguação da condição de mercado conforme a metodologia, sugere-se um debate de um comitê de rating - algo não existente para a condução desse estudo de caso. Entretanto, da mesma forma, essa ausência não deve ser considerada como impeditivo da metodologia.

Conforme apresentado, durante a aplicação da metodologia, alguns indicadores não puderam ser calculados de imediato, pois a cooperativa não possuía informações suficientes naquele momento ou determinada informação não estava disponível em fontes secundárias. Porém, esse fato não invalidou a sua aplicação, pois ocorreu até o contrário: conforme observado pelos próprios profissionais da cooperativa, os indicadores são relevantes, possíveis de serem obtidos e deveriam ser levados em consideração. A cooperativa obteve as avaliações a, b e c, não havendo concentração numa única avaliação. A distribuição delas permitiu inferir que a cooperativa possui pontos que a expõem ao risco e outros que garantem o cumprimento dos seus compromissos.

A partir das avaliações recebidas em cada um dos tópicos, foram emitidas as avaliações para os grupos, conforme a Tabela 3.

A Tabela 4 mostra as avaliações finais atribuídas a cada um dos grupos de análise na cooperativa. A avaliação B para a capacidade de organização apresentou a real situação da cooperativa em termos de gestão, pois durante as visitas se averiguou um grande esforço por parte de diretores e funcionários para gerirem adequadamente $o$ empreendimento. Entretanto, a qualidade e o número de instrumentos utilizados para realizar a gestão, bem como a tomada de decisão, tornam a sua eficácia reduzida.

O capital da cooperativa, nota $\mathrm{B}$, apresentou a atual situação do capital da cooperativa, comprovado pela sua solvência e liquidez (Índice de Solvência representado por Kanitz foi de 5,0 e Liquidez Corrente = 1,3). Porém, se houver mudanças no cenário, o empreendimento, graças à falta de capital de giro e capital do cooperado para ser utilizado nas suas atividades, poderá apresentar dificuldades financeiras operacionais.

O caráter da cooperativa com avaliação A aponta que a cooperativa pode ser caracterizada como cumpridora de seus
Tabela 3. Tópicos, indicadores e avaliação atribuídos à cooperativa, estudo de caso.

\begin{tabular}{|c|c|c|}
\hline Tópicos & Indicadores & $\begin{array}{c}\text { Avaliação do } \\
\text { tópico }\end{array}$ \\
\hline Eficiência Social (ES) & $\begin{array}{l}\text { ATc } \\
\text { PAG }\end{array}$ & $\mathrm{C}$ \\
\hline $\begin{array}{l}\text { Estratégia Empresarial } \\
\text { da Cooperativa com o } \\
\text { Cooperado } \\
\text { (EECC) }\end{array}$ & $\begin{array}{c}\text { CFCC } \\
\text { ECVC } \\
\text { PDCC } \\
\text { RCSC } \\
\text { PSC } \\
\text { CFINC }\end{array}$ & B \\
\hline $\begin{array}{l}\text { Eficiência Empresarial } \\
\text { enquanto Organização } \\
\text { (EEO) }\end{array}$ & $\begin{array}{l}\overline{\mathrm{IPM}} c \\
\mathrm{CFIN} \\
\mathrm{MOC} \\
\mathrm{GAP}\end{array}$ & B \\
\hline $\begin{array}{l}\text { Profissionalização e } \\
\text { Qualidade da Governança } \\
\text { (PQG) }\end{array}$ & $\begin{array}{l}\text { RCE } \\
\text { FHE } \\
\text { EFG }\end{array}$ & B \\
\hline $\begin{array}{l}\text { Capital Social do Cooperado } \\
\text { (CSC) }\end{array}$ & $\begin{array}{l}\mathrm{CS}_{\mathrm{C}} \\
\mathrm{CSG}\end{array}$ & $\mathrm{C}$ \\
\hline Endividamento (END) & $\begin{array}{l}\text { GCFE } \\
\text { DLPC } \\
\text { GDTer }\end{array}$ & $\mathrm{C}$ \\
\hline $\begin{array}{l}\text { Autofinanciamento } \\
\text { (AUTFIN) }\end{array}$ & IAF & $\mathrm{C}$ \\
\hline Liquidez (LIQ) & $\begin{array}{l}\mathrm{LC} \\
\mathrm{LS}\end{array}$ & B \\
\hline Rentabilidade (RENT) & $\begin{array}{l}\text { MgL } \\
\text { RSA } \\
\text { RSPL }\end{array}$ & A \\
\hline Solvência (SOLV) & KANITZ & A \\
\hline Pontualidade & & A \\
\hline Protestos e desabonos & & A \\
\hline
\end{tabular}

Tabela 4. Avaliações finais atribuídas a cada um dos grupos de análise na cooperativa.

\begin{tabular}{lc}
\hline \multicolumn{1}{c}{ Grupo } & Avaliações \\
\hline Capacidade da Organização Cooperativa & $\mathrm{B}$ \\
Capital da Organização Cooperativa & $\mathrm{B}$ \\
Caráter da Organização Cooperativa & $\mathrm{A}$ \\
Colateral e Conglomerado & $\mathrm{B}$ \\
Condição do mercado & $\mathrm{A}$ \\
\hline
\end{tabular}

compromissos. A não consulta de fontes de informações privadas relativas a um possível histórico negativo não limitou a nota, uma vez que seus indicadores de solvência, liquidez e rentabilidade foram bastante satisfatórios. Além do Índice de Liquidez Corrente e de Solvência já referidos, a cooperativa ainda apresentou os seguintes indicadores de 
rentabilidade: $\mathrm{MgL}=4,16 \%$; $\mathrm{RSA}=6 \%$, e $\mathrm{RSPL}=35,5 \%$. Contudo, não se descarta que maior grau de confiabilidade ocorra à medida que se acessem aquelas informações.

No quarto grupo de análise, a avaliação B mostra que o nível de garantia e colateral é adequado às dívidas assumidas, o que é corroborado pelos índices de solvência e liquidez e pela nota da capacidade da organização. Entretanto, devido ao fato de essa nota ter sido baseada apenas nos questionamentos efetuados pelo pesquisador, não é possível inferir a sua veracidade, uma vez que as análises de peritos nesta área, bem como a avaliação de documentos comprobatórios, poderiam apontar uma nota diferente. Portanto, a nota B recebida nesse item precisaria ter sustentação de avaliações com maior embasamento técnico, para ser considerada em tomadas de decisões relacionadas à realização de contratos com a cooperativa.

Por fim, a avaliação A para a condição de mercado informou que a cooperativa atua em um mercado com condição propícia, ou seja, que permite cumprir seus compromissos de curto prazo.

A combinação dos resultados apresentados pela cooperativa e a experiência da aplicação do estudo de caso permitiram apontar que os indicadores previstos para informar a capacidade e o capital da organização se mostraram consistentes com a realidade da cooperativa e que os indicadores do caráter apresentaram a necessidade de uma avaliação rigorosa acerca da veracidade dos documentos comprobatórios. Os indicadores que servem para nortear as avaliações do conglomerado e colateral e as condições de mercado, por necessitarem de conhecimento mais detalhado e específico do avaliador, apontaram a importância da criação de comitês para avaliar em conjunto as informações, de forma semelhante à que as agências de rating procedem.

Os grupos, da forma como foram definidos, acompanhando os C's do crédito, também foram adequados, pois abrangeram praticamente todas as áreas da organização, inclusive a influência do mercado na atividade da cooperativa.

Pode-se, ainda, constatar a aplicabilidade da metodologia e a sua capacidade de explicação da situação da cooperativa, quando se analisa a trajetória da cooperativa estudo de caso, que está relacionada entre as 500 maiores empresas de agronegócios, segundo o Anuário Exame 2008-2009 (2008). Assim, essa cooperativa teve não somente um bom desempenho nos anos analisados como em anos posteriores, de forma congruente com que a proposta metodológica também apontou. Também há o fato de que a cooperativa está relacionada entre as melhores organizações setoriais no agronegócio Café e, de acordo com a metodologia proposta pela FIPECAFI - Fundação Instituto de Pesquisas Contábeis, Atuariais e Financeiras - e com o Anuário Exame 2008-2009 (2008), recebeu a segunda maior pontuação. Este importante reconhecimento levou em consideração indicadores de crescimento de vendas, liderança de mercado, liquidez corrente, liquidez geral, rentabilidade, reposição da capacidade produtiva e riqueza por empregado. Essas evidências corroboram a aplicação da metodologia proposta.

Em termos gerais, pode-se apontar que a metodologia é aplicável, apresenta uma aproximação da realidade do mercado e deverá provavelmente servir como mecanismo para reduzir a assimetria de informações entre diretores, cooperados e mercado.

\section{Considerações finais}

Para as cooperativas brasileiras, não existe uma metodologia de rating, mas sim trabalhos científicos e empíricos que objetivam analisar sua condição de solvência ou capacidade de pagamento e avaliá-las para fins de prestação de serviços em assessoria na gestão. É notório, porém, que esses trabalhos não levam em consideração a sua especificidade enquanto empreendimento cooperativo.

A metodologia criada teve maior enfoque na proposição de indicadores específicos para cooperativas agropecuárias e na manutenção dos chamados indicadores tradicionais. Pode ser caracterizada como abrangente, pois os indicadores propostos envolveram todas as áreas de gestão da cooperativa estudada. O teste de aplicação da metodologia, por meio de um estudo de caso, mostrou que, inicialmente, os indicadores previstos na metodologia são possíveis de serem calculados junto às cooperativas, desde que estas tenham um nível de controle de informações minimamente organizado.

A forma como a metodologia foi proposta, no que se refere ao método de gerar pesos e avaliações por segmento, mostrou-se bastante interessante, pois se tornou moldável a entrada ou saída de indicadores ou de tópicos a serem calculados, além de informar o rating por segmento de análise. As avaliações finais, apresentadas no caso da cooperativa estudada, poderão ser usadas como uma fonte de informações acerca de diversos aspectos de sua gestão e, portanto, servem como redutores da assimetria de informação. Mas é importante lembrar que a descrição de procedimentos do avaliador e a formação de comitê de rating deverão também contribuir para enriquecer a metodologia e possibilitarão sua comparação quando aplicada a diferentes tipos de cooperativas.

Pode-se considerar que para a metodologia de rating proposta, ser mais largamente aplicável, esta deverá ser avaliada em estudos estatísticos e quantitativos amplos, e de forma temporal. Para finalizar, é importante considerar não somente a importância do rating, mas também se deve atentar para uma agenda futura de pesquisa no que tange à possibilidade de criar instrumentos e mecanismos que possibilitem às cooperativas - a exemplo do que ocorre entre a Comissão de Valores Mobiliários (CVM) e as empresas de capital aberto - apresentar informações assimiláveis de seu desempenho, tanto para o mercado como - e principalmente para os seus cooperados, haja vista o nível de importância que essa informação apresenta para ambos. 


\title{
Rating methodology in agricultural cooperatives: a case study
}

\begin{abstract}
Owing to macroeconomic problems in Brazil in the late nineties, some modifications occurred in the agricultural cooperatives institutional environment that had influence on debt level and compromised the cooperative enterprises leverage on financial market resources. This situation has improved, in recent years, to maintain cooperatives' organizational competition level in markets. Owing to the significant implications of this important new business environment, this paper tries to discuss the tools to reduce the information asymmetry among cooperatives and the financial markets agents. In this way, developing a rating methodology applied to agricultural cooperatives in Brazil to reduce moral hazard and adverse selection that creates business and contractual organizational inefficiency among cooperatives and financial markets agents. The 'five C' method was used which considers organizational financial capacity, corporate governance characteristics, relations with members, and commodity market characteristics, among others. A weighting and evaluation were associated with each variable. The result was applied to an agricultural cooperative case study which concluded that this methodology is applicable and that results, evaluations and weights, could be discussed in cooperative rating committees. As a final consideration, an agenda is discussed for new applications of this methodology, for testing in other agricultural cooperative organizations and to consolidate it as a market financial information signal.
\end{abstract}

Keywords: Cooperatives. Rating. Auditing. Risk.

\section{Referências bibliográficas}

AKERLOF, G. A. The market for lemons: quality uncertainty and the market mechanism. Quarterly Journal of Economics, v. 84, n. 3, p. 488-500, 1970.

ANUÁRIO EXAME 2008-2009. São Paulo: Editora Abril. 2008. $170 \mathrm{p}$.

ARAUUJO, U. M. Assimetria de informação no crédito rural: aspectos teóricos e um modelo de classificação dos riscos dos créditos concedidos a cooperativas agropecuárias. Piracicaba, 1996. 81 p. Tese (Doutorado) - Escola Superior de Agricultura "Luiz de Queiroz", Universidade de São Paulo.

BERGAMINI JUNIOR, S. Classificação de risco: o modelo em uso no BNDES. 2000. Disponível em: <http://www.bndes.gov.br/ conhecimento/publicações/catalogo/rev_10a6.asp>. Acesso em: 20 Outubro 2004.

BIALOSKORSKI NETO, S. Agribusiness cooperativo: economia, doutrina e estratégias de gestão. Piracicaba, 1994. 135 p. Dissertação (Mestrado) - Escola Superior de Agricultura "Luiz de Queiroz", Universidade de São Paulo.

BIALOSKORSKI NETO, S. (Ed.). Política institucional de monitoramento da autogestão das cooperativas do Estado de São Paulo: uma proposta preliminar de metodologia, pesquisa e implantação. São Paulo: [s.n.], 2000. 127 p.

BIALOSKORSKI NETO, S.; NAGANO, M. S.; MORAES, M. C. B. Utilização de redes neurais artificiais para avaliação socioeconômica: uma aplicação em cooperativas. RAUSP, v. 41, n. 1, 2006.

COSTA, D. R. M. Rating de Cooperativas Agropecuárias: uma contribuição metodológica. Piracicaba, 2005. 260 p. Dissertação (Mestrado) - Escola Superior de Agricultura "Luiz de Queiroz", Universidade de São Paulo.

COSTA, D. R. M.; BIALOSKORSKI NETO, S. Assimetria de informação no cooperativismo agropecuário brasileiro: origem, implicações e soluções In: Congresso da Sociedade Brasileira de Economia e Sociologia Rural, XLII, 2004, Cuiabá, MT. Anais... Cuiabá: UFMT e UERJ, 2004.

FISCHER, M.; MOORE, K. An improved credit scoring function for the St. Paul Bank of cooperatives. Journal of the Agricultural Cooperative, v. 1, p. 11-21, 1986.
GIMENES, R. M. T.; OPASO, M. A. U. Modelos multivariantes para a previsão de insolvência em cooperativas agropecuárias: uma comparação entre a análise discriminante e a análise de probabilidade condicional - Logit. Caderno de Pesquisa em Administração, v. 8, n. 3, p. 65-76, 2001.

MENEGÁRIO, A. H. Emprego de indicadores sócio-econômicos na avaliação financeira de cooperativas agropecuárias. Piracicaba, 2000. 121 p. Dissertação (Mestrado) - Escola Superior de Agricultura “Luiz de Queiroz”, Universidade de São Paulo.

MILGROM, P.; ROBERTS, J. Economics, organization \& management. New Jersey: Prentice Hall, 1992. 619 p.

MOODY'S INVESTORS SERVICE. Rating actions. Disponível em: <http://www.moody's.com>. Acesso em: 25 Março 2004.

OLIVEIRA JUNIOR, C. C. Avaliação da eficiência empresarial das cooperativas. Curitiba: OCEPAR, 1991. 80 p.

ORGANIZAÇÃO DAS COOPERATIVAS DO ESTADO DE SÃO PAULO - OCESP. Coleção jurídica: legislação cooperativista. São Paulo, 2002. 94 p.

REQUEJO, L. M. H. Lack of monitoring agricultural cooperatives in Brazil: evidence and prospects for improvement. 1997. Disponível em: <http://www.agrosoft.org.br/trabalhos/ag97/w@w1600.htm>. Acesso em: 10 Outubro 2004.

SILVA, J. P. da. Análise e decisão de crédito. São Paulo: Editora Atlas, 1997. 388 p.

SPENCE, A. M. Market signaling: information transfer in hiring and related processes. Cambridge: Harvard University Press, 1973. $221 \mathrm{p}$

STIGLITZ, J. E.; WEISS, A. Credit ration in market with imperfect information. The American Economic Review, v. 71, n. 3, p. 393-410, 1981.

WESTON, J. F.; BRIGHAM, F. E. Fundamentos da administração financeira. Tradução de S. de Stancatti. São Paulo: Makron Books do Brasil Editora Ltda, 2000. 1030 p. 


\section{Anexo}

Índice de atividade econômica do cooperado com a cooperativa - Atc

\section{Indicador}

Fórmula

Índice de abrangência do quadro social - AQS

Índice de participação dos cooperados em assembleia geral - PAG

Eficiência Social da cooperativa - ES

Índice de cobertura do financiamento efetuado pela cooperativa ao cooperado - CFCC

Ciclo financeiro da cooperativa junto ao cooperado - CFINC

Índice de participação média da cooperativa no mercado regional $-\overline{\mathrm{IPM}} c$

Ciclo financeiro da cooperativa - CFIN

Margem operacional da cooperativa - MOC

Giro dos ativos permanentes - GAP

Capital social por cooperado - CSc

Capital social utilizado no giro - CSG

Grau de comprometimento do faturamento bruto da cooperativa com o endividamento total junto a terceiros - GCFE

Distribuição do endividamento total quanto ao curto - DCPC

Distribuição do endividamento total quanto ao longo prazo - DLPC

Grau de dependência de capital de terceiros para operacionalizar suas atividades - Gdter

Capital de giro disponível - CGD

Necessidade de capital de giro - NCG

Índice de autofinanciamento - IAF

Índice de Liquidez Corrente - LC

Índice de Liquidez Seca - LS

$A T c=\frac{N C_{a}}{N C_{t}}$

$A Q S=\frac{N C_{t}}{N P_{t}}$

$P A G=\frac{C A p_{t}}{N C_{t}}$

$E S=\frac{1}{n} \sum_{i=1}^{n} X_{i}$

$C F C C=\left(\frac{G D C}{D C C}\right)$

$C F I N C=P M R C+P M E c-P M P C$

$$
\overline{I P M}_{c}=\frac{\left(\sum_{t=1}^{n}(I P M)_{t} \times(P)_{t}\right)}{\sum_{t=1}^{n}(P)_{t}}
$$

$C F I N=P M R+P M E-P M P$

$M O C=\left(\frac{(R T-C M V-D O)}{R T}\right) \times 100$

$$
G A P=\frac{V P}{A P}
$$$$
C S_{c}=\frac{C S_{r}}{N C_{t}}
$$

$$
C S G=\frac{C S_{r}}{N C G}
$$

$G C F E=\left(\frac{P C+E x L P z}{F a t B}\right) \times 100$

$$
D C P C=\left[\frac{P C}{P C+E x L p z}\right]
$$$$
D L P C=\left[\frac{E x L P z}{P C+E x L P z}\right]
$$

GDTer $=\left[\frac{(P C+E x L P z)}{P L}\right]$

$C G D=\frac{[(P L+E x L p)-(A P+R L p)] \times 100}{A T}$

$N C G=\left(\frac{A O-P O}{A T}\right) \times 100$

$I A F=\frac{C G D}{N C G}$

$L C=\frac{A C}{P C}$

$L S=\frac{(A C-E s t)}{P C}$ 
Anexo. Continuação...

\begin{tabular}{lc}
\hline \multicolumn{1}{c}{ Indicador } & Fórmula \\
\hline Margem líquida - MgL & $M g L=\frac{(S O B a)}{V T}$ \\
Retorno sobre os ativos - RSA & $R S A=\frac{(S O B r e i)}{A T}$ \\
Retorno sobre o patrimônio líquido - RSPL & $R S P L=\frac{(\text { SOBrei, }}{P L}$ \\
Índice de Kanitz & $K=0,05 R K p+0,65 L G+3,55 L S+1,06 L C-0,33 E T$ \\
\hline
\end{tabular}

\section{Sobre os autores}

\section{Davi Rogério de Moura Costa}

Economia Aplicada, Escola Superior de Agricultura "Luiz de Queiroz" - ESALQ, Economia de Empresas Escola de Economia de São Paulo - EESP, Fundação Getulio Vargas - FGV-SP, Universidade de São Paulo - USP Av. Pádua Dias, 11 CP 9, CEP 13418-900, Piracicaba, SP, Brasil e-mail: drmcosta@gvmail.br

\section{Sigismundo Bialoskorski Neto}

Faculdade de Economia, Administração e Contabilidade de Ribeirão Preto, Universidade de São Paulo - USP Av. Bandeirantes 3900, Monte Alegre, CEP 14040-900, Ribeirão Preto, SP, Brasil e-mail: sigbial@fearp.usp.br

Agradecimentos: Os autores agradecem pelo apoio da Organização das Cooperativas do Estado de São Paulo (OCESP) e do Serviço Nacional de Aprendizagem do Cooperativismo (SESCOOP), bem como aos membros da cooperativa, estudo de caso, que gentilmente forneceram tão relevantes informações. 